\title{
MAPPING RECURRENT FLOODING ZONE ALONG ESTONIAN INLAND WATERS FROM SENTINEL-1 AND -2
}

\author{
L. Sipelgas ${ }^{1}$, A. Aavaste ${ }^{1}$, R. Uiboupin ${ }^{1}$ \\ ${ }^{1}$ TalTech, Department of Marine Systems, Tallinn, Estonia - (liis.sipelgas, age.aavaste, rivo.uiboupin)@ taltech.ee
}

KEY WORDS: Flood Mapping, Sentinel-1, Sentinel-2, Spatial planning

\begin{abstract}
:
In the process of spatial planning in Estonia the local municipalities are required to define the recurrent flooding zone along the inland waters that locate at their territory. Estonia is well known for its large floodplains that are annually covered by water. However, information about the spatial flood extent is scarce. A methodology for mapping the flooded area from Sentinel-1 and -2 imagery was developed and applied on data covering high water seasons in 2016-2019. Statistical information about flooded areas along the inland waters were compared with other available data sources related to wetlands i.e. map of wetlands in Estonian Topographic Database. Results showed that additional information about flood extent and duration retrieved from Sentinel-1 and Sentinel-2 the data can contribute to defining the recurrent flooding zone along the inland waters in process on spatial planning.
\end{abstract}

\section{INTRODUCTION}

Floods can be considered the most frequent, disastrous, and widespread natural hazard that often results in significant economic losses (Martins et al., 2015). Floods play a crucial role not only in the context of disaster. In tropical and subtropical regions, large areas are frequently inundated due to monsoon driven rainy season. Extreme changes in inundation extent, depth, and duration define phonological pattern, animal migration routes, and human living space (Thenkabail, 2016).

Monitoring of flood extent and dynamics in time is needed for effective risk management. Near real-time spatial information about flooded areas is essential for several public services: i.e. emergency, recovery, spatial planning. Satellite remote sensing can provide timely and operational spatial information about areas covered with water. Monitoring of flooded areas from satellites, both optical and radar remote sensing instruments, has been subject of several research projects, and papers worldwide (Brisco et al., 2008, Clement et al., 2017, Feyisa et al., 2014 , Henry et al., 2006, Martins et al., 2009, Manjusree et al., 2012, Martins et al., 2015, Pham-Duc et al., 2017, Pulvirenti et al., 2011, Sanyal et al. 2004, Twele et al., 2016, Xu, 2006). Optical satellite remote sensing can be applied only in cloud-free situations. However, floods often occur during long-lasting periods of precipitation and persistent cloud cover, therefore spaceborne Synthetic Aperture Radar (SAR) systems are usually a preferred tool for observing flood situations from space. Recently European Space Agency together with European Commission have launched Copernicus Sentinel series satellites that show great potential for flood monitoring. Sentinel-1 and -2 satellites provide systematic acquisition capabilities and the acquired data is also free of charge. The Sentinel -1 mission that carries C-band SAR sensor provides routine data in two imaging modes: interferometric wide swath mode (IW) and extended wide swath mode (EW). The pixel spacing of the IW mode is $5 \times 20$ meters, while the spatial resolution of gridded EW mode data is 40 meters (Geudtner et al., 2014). The Sentinel-2 optical data that is beneficial during cloud-free conditions has spatial resolution of 10 meters. The high spatial resolution data and sufficient repeat cycle of Sentinel-1 (12 days with one satellite and 6 days with 2 satellites) and Sentinel-2
(10 days with one satellite and 5 days with 2 satellites) missions form a solid basis for statistical flood mapping applications and operational flood monitoring service (Zoka et al., 2018).

Estonia is known for its large seasonal riverside areas that are annually flooded over. According to the EU Habitats Directive, 'Northern boreal alluvialmeadows' (habitat type code 6450) are grasslands situated on the banks of large rivers, in sections with slow flow, which are frozen in winter and flooded in the springsummer period. Floodplain grasslands can be found all over Estonia, most of them lie on the floodplains of larger riversEmajõgi, Põltsamaa, Pedja, Kasari, Halliste, Raudna, Piusa, Koiva, Mustjõgi, Narva headwaters-but also near lakes (Peipsi, etc.). The surface area of Estonian floodplain grasslands with a high nature conservation value is estimated to be 16,000 hectares. Those grassland floodplains have cultural (touristic) and natural (species conservation) importance. The habitats of floodplain grassland vegetation are considerably more varied in comparison to boreo-nemoral grasslands-26 different plant communities have been noted as opposed to the 13 of boreonemoral grasslands. Approximately 20-22, maximally 30 bird species are native to floodplains in Estonia.

Spatial planning of inland floodplains in Estonia is a challenging task because of the conflict of interests between economic and nature conservation aspects. According to legislative acts, the local municipalities are required to define the recurrent flooding zone along the river banks that locate at their territory. The spatial information about the extent of flooded areas (especially along the smaller rivers) is scarce and water level measurements are limited (only available for a number of large rivers). Previously application of remote sensing method for flood monitoring in Estonia have been described in $\mathrm{PhD}$ theses by Voormasik (2014) and Zalite (2016).

In 2019 Ministry of Environment in Estonia initiated the project "Mapping recurrent flooding zone of inland waters from Sentinel-1 and -2" with the aim to collect statistical information about flooded areas from Earth Observation data. This paper is an overview of the project results. 


\section{DATA AND METHODS}

\subsection{Data}

Different sources of data, both Earth Observation (EO) and insitu, were used in the current analysis. Water level data from 26 hydro-meteorological stations in Estonia were analysed to identify potential flood periods during 2016-2019. Sentinel-1 C-band radar data in IW (Interferometric Wide Swath) and EW (Extra-Wide Swath) sensing mode and cloud-free Sentinel-2 MSI (Multispectral Imager) data for the flood periods were downloaded from EstHub (Estonian Satellite Data Centre) for high water level periods in 2016-2018.

Maps of wetlands and shorelines were downloaded from the Estonian Topographic Database (ETD, https://geoportaal.maaamet.ee/eng/Spatial-Data/Estonian-

Topographic-Database-p305.html). In addition, map of floodplains compiled during the project "Estimation of Estonian wetlands status and determination of their management options" by the Institute of Ecology at Tallinn University was used in our analysis (https://www.etis.ee/Portal/Projects/Display/41a457226bd8-4d95-abe8-d1ed8d34f5a5?lang=ENG).

\subsection{Methods}

\subsubsection{Satellite data processing}

The data processing scheme (Figure 1) for flood mapping from Sentinel-1 included the following steps: radar signal calibration, noise filtering, terrain correction, and image processing technical procedures: reading, cutting, and extracting data (Pham-Duc et al., 2017). Data processing was performed using SNAP (Sentinel Application Platform) software. The sensitivity of different Sentinel-1 SAR polarizations and their combinations to distinguish between water and land was evaluated after pre-processing. Our tests indicated that the most suitable/sensitive polarizations of Sentinel-1 C-band radar data for discrimination land and water were VH (IW mode) and HV (EW mode). After pre-processing of Sentinel-1 images the threshold value for water detection was determined depending on the radar beam incidence angle. The images were tiled according to incidence angle and the threshold value for water was set separately for each tile using bimodal histogram analysis (Chini, et al., 2017).

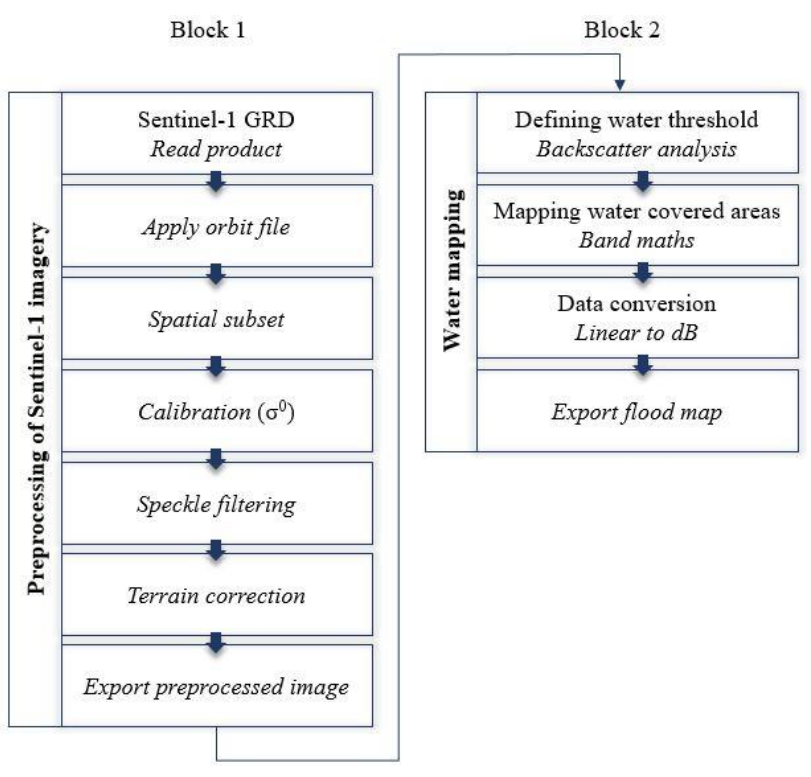

Figure 1. Sentinel-1 data processing scheme

Different vegetation indexes were tested for water mapping from Sentinel-2 data. Our testes indicated that MNDWI (Du et al., 2016, Eq. 1) index is most suitable for water mapping from Sentinel2- MSI imagery:

$M N D W I=($ Band $3-$ Band 11$) /($ Band $3+$ Band 11$)$

Post-processing of Sentinel-1 and -2 data was done according to the block scheme in Figure 2 using QGIS software. Preclassified satellite data was vectorized and only the polygons that were related to rivers were extracted for further analysis. Finally, the water polygons were merged and map with recurrently flooded areas along the Estonian rivers observed from Sentinel-1 (S1) and Sentinel-2 (S2) database were compiled.

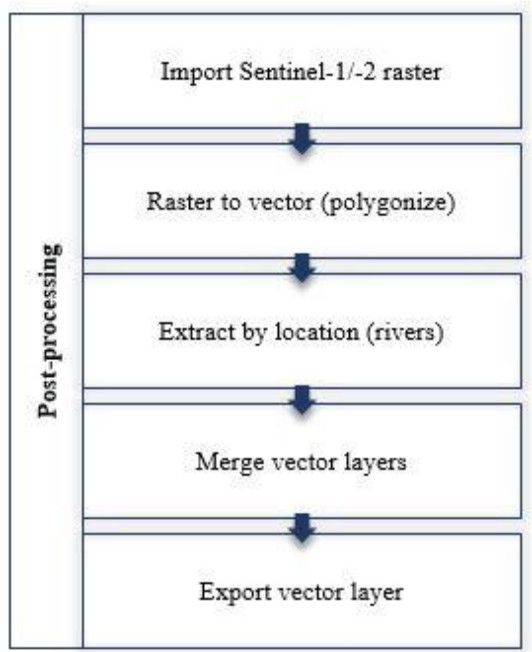

Figure 2. Sentinel-1 and Sentinel-2 post-processing scheme

\subsubsection{Accuracy assessment of flood mapping}

The accuracy of flood mapping was evaluated by estimating the overall accuracy and kappa hat coefficient. For accuracy assessment, the Semi-Automatic Classification Plugin in QGIS was used.

\section{RESULTS}

\subsection{Comparison of flood mapping results from Sentinel-1 and Sentinel-2.}

On Figure 3 is shown the water mapped from Sentinel-1 (24.03.2019) and Sentinel-2 (24.03.2019) near Kasari River floodplain together with official shoreline from Estonian Topographic Database. Figure 3 illustrates that the general coincidence of water mapped from Sentinel-1 and Sentinel-2 was good, the corresponding overall accuracy is $95.9 \%$ and kappa hat coefficient 0.86 . However, it is well seen that the area mapped as water on Sentinel-1 and Sentinel-2 data on 24.03.2019 exceeds largely the official shoreline (from ETD) of River Kasari (Figure 3). Figure 4 shows the area that is mapped as water on Sentinel-1 and Sentinel-2 images at Soomaa test site. The coincidence of water mapped from Sentinel-1 and Sentinel-2 at Soomaa test site was not that good, with accuracy being 93.6 and kappa hat coefficient 0.62 . Lower accuracy can be explained with the vegetation shadow effect on the Sentinel- 
2 MNDWI index. Vegetation shadows caused high MNDWI values that were classified as water. The third example is from river Emajõgi test site (Figure 5). On that test site, the overall accuracy of water mapped from S1 compared to S2 was again very high $(96.7 \%)$ with kappa hat coefficient of 0.84 .

Data presented on figures 3,4 and 5 illustrates the relatively good agreement between water mapped from Sentinel-1 and Sentinel-2 and thus confirms the reliability of radar satellite data for water mapping. However, data also indicates that in many cases the information about river shoreline in topography map (ETD) is not enough to define the recurrent flooding zone in the process of spatial planning.

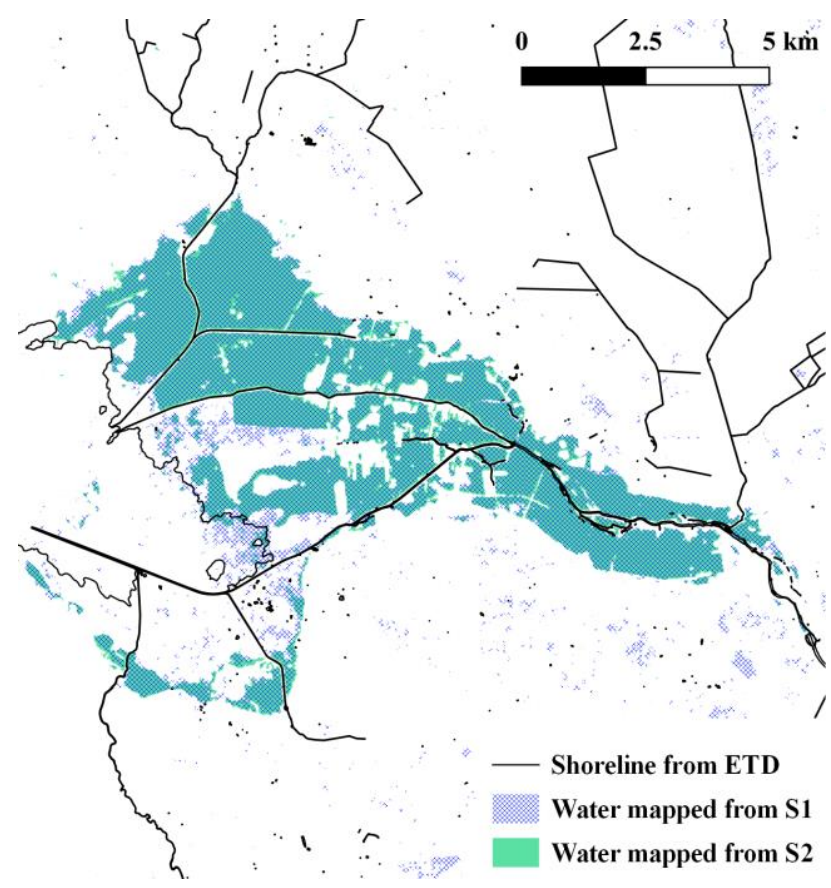

Figure 3. Water mapped on 24.03.2019 from Sentinel-1 IW image (VH polarization) and Sentinel-2 image

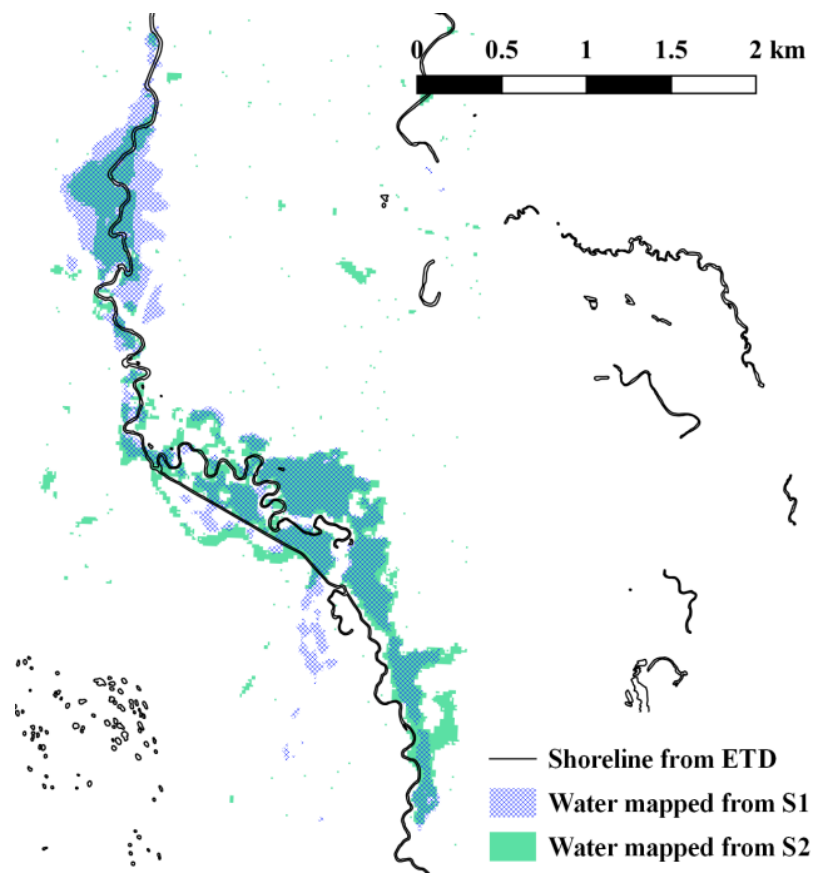

Figure 4. Water mapped on 16.11.2017 from Sentinel-1 IW image (VH polarization) and Sentinel-2 image

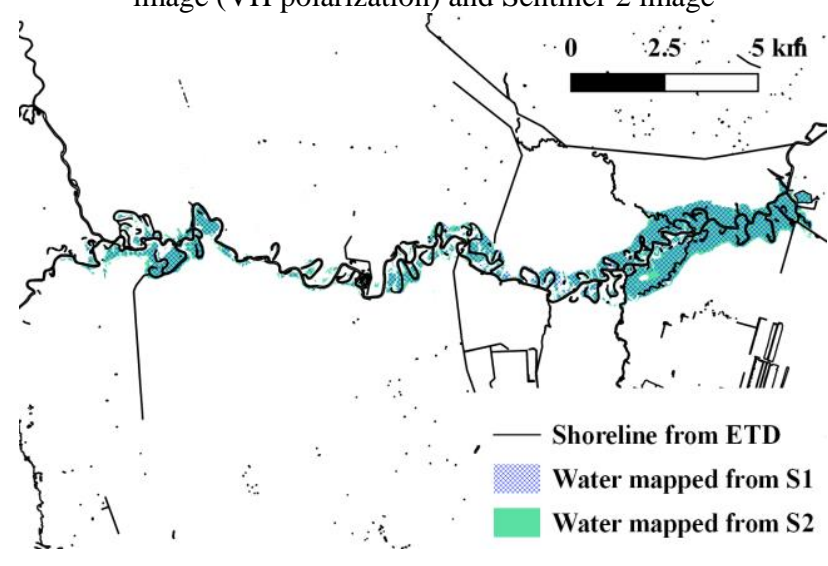

Figure 5. Water mapped on 05.04.2019 from Sentinel-1 IW image (VH polarization) and Sentinel-2 image

3.2 Comparison statistical flood extent map form Sentinel-1 and Sentinel-2 data with wet area maps compiled with different methodology.

The water extent was mapped from 85 Sentinel-1 and -2 images according to the methodology described in section 2.2. By merging all derived flood maps we compiled statistical flood map for Estonia from Sentinel-1 and -2 data (Figure 6). Figure 6 indicates three large floodplains Kasari, Alam-Pedja and Soomaa (marked with a red rectangle) that are recurrently flooded over.
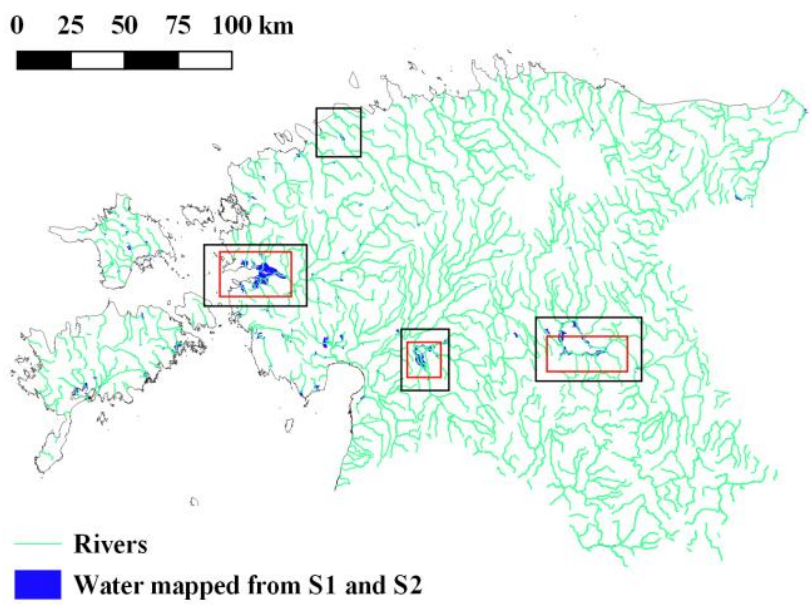

Figure 6. Statistical flood extent map from Sentinel-1 and Sentinel-2 data

At four test sites (marked in a black rectangle in Figure 6) we compared the statistical flood map compiled from S1 and S2 data with alternative information that represent wet areas. One available source of information about wetlands is Estonian Topographic Database, where wetlands are mapped relying on vegetation information that is retrieved by means of visual interpretation of areal photographs. In addition, map of Estonian riverside floodplains has been compiled during the project "Estimation of Estonian wetlands status and determination of their management options" in 2013 (Lode et al., 2012). In this project, floodplains were also mapped relying 
on vegetation information retrieved from aerial photographs (provided by Estonian Land Board), soil map and visual inspection of vegetation at the site. This map will be referred as "Floodplain Tallinn University map". We compared those three different information sources that all indicate temporarily wet areas along four test sites. Figure 7 illustrates different wet area maps form the Emajõgi River test site. Figure 7 shows that near Emajõgi River (marked as a red rectangle on Figure 7) the coincidence of different maps is good. So, all mapping methodologies indicated the temporarily water covered areas inside red rectangle on Figure 7. The other example is Keila River (Figure 8). In this case, the Sentinel-1 and Sentinel-2 map showed that the part of River Keila is temporarily flooded over. However, the area was not mapped as a wetland on ETD or floodplain area on the Tallinn University Floodplain map. Note that in both cases also the temporarily water covered area exceeds the official shoreline as mapped on ETD. The third example is related to rivers of Halliste, Raudna and Lemmjõgi at Soomaa floodplain (Figure 9). Figure 9 shows that some parts of these rivers (marked in red rectangles) are mapped as floodplains on Tallinn University Floodplain map. Still, in some areas (marked with a black rectangle) on Figure 9 the flood was observed only from satellite data. Also, floods mapped from Sentinel-1 and -2 exceeded widely the official shoreline (as mapped on ETD database). The fourth example is from River Kasari test site (Figure 10). On figure, it is seen that there was a good coincidence between Floodplain Tallinn University map and flooded area mapped from Sentinel-1 and -2 data. However, the official shoreline of Kasari River (from ETD) is exceeded repeatedly.

Those were just four examples where possibly flooded areas mapped with different methodologies gave controversial information about the recurrently flooded areas along the shoreline of inland waters in Estonia. From our analysis, we could learn that the official shoreline (source ETD) information is not enough for defining the recurrent flooding zone along the Estonian rivers and different sources of information is needed.

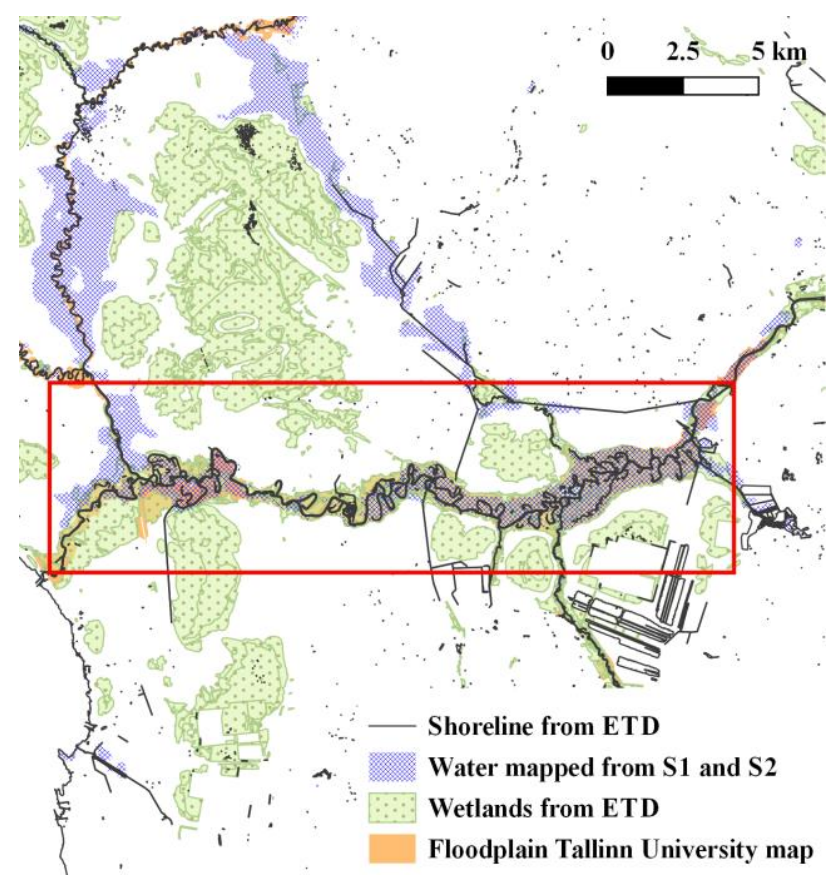

Figure 7. River Emajõgi at different maps

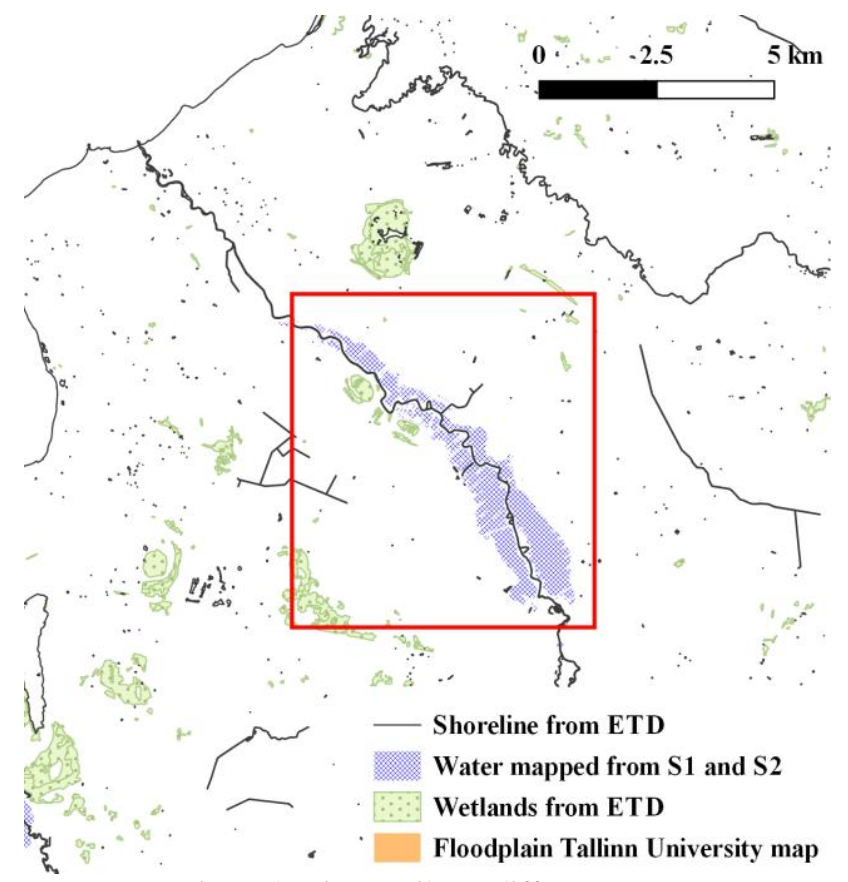

Figure 8. River Keila on different maps

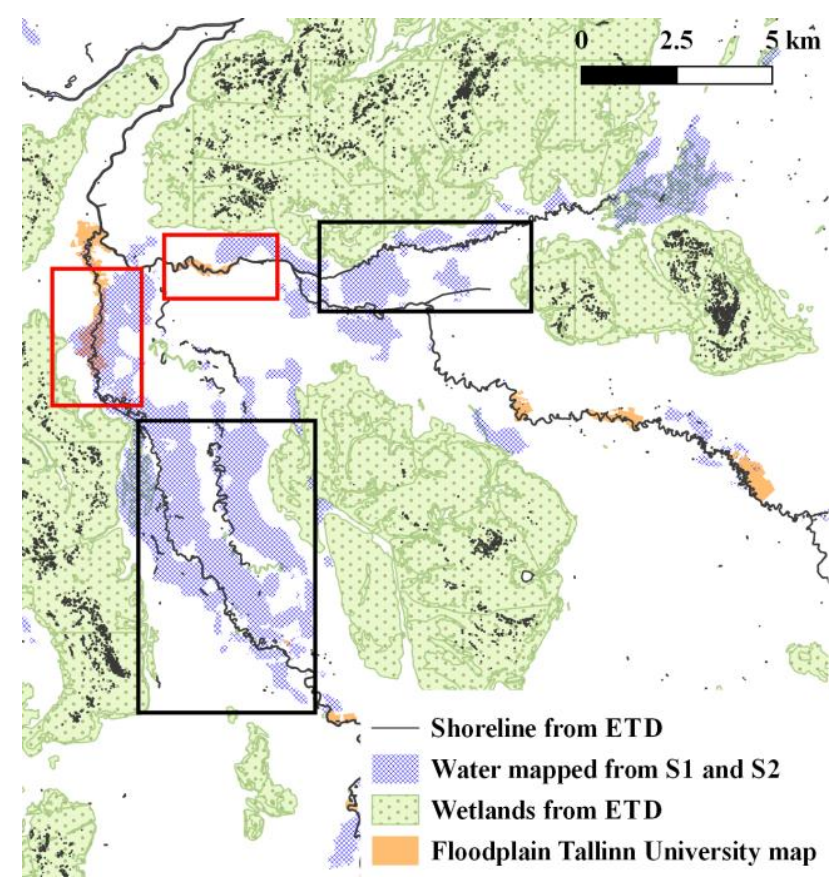

Figure 9. Rivers Halliste, Raudna and Lemmjõgi on different maps 


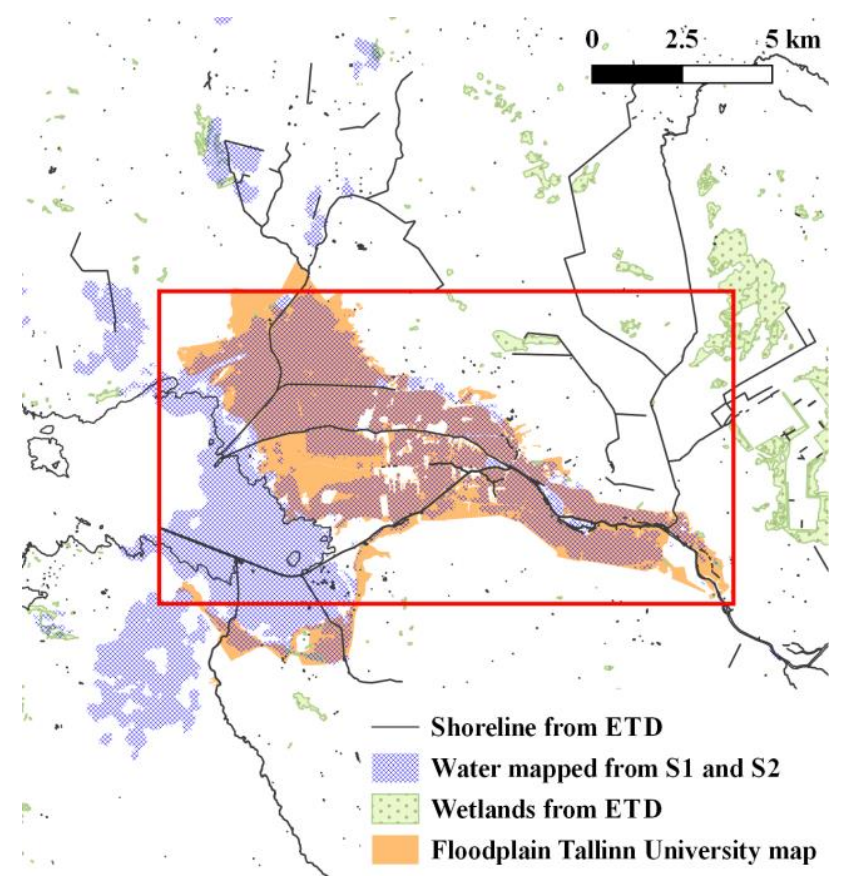

Figure 10. River Kasari on different maps

\section{CONCLUSIONS}

Defining the recurrent flooding zone along the shorelines of inland waters in Estonia is crucial because of the seasonal and inter-annual variability of water level. Currently, there is no official method or guideline how the recurrently flooded area should be evaluated in the process of spatial planning in Estonia. We mapped water extent along Estonian rivers during high water seasons in 2016-2018 from Sentinel-1 and Sentinel2 data. From Sentinel-2 the water was mapped for cloud-free days using MNDWI index. Water was mapped from Sentinel-1 data using VH polarisation (IW mode) and HV polarisation (EW mode). Sentinel-1 images were tiled according to incidence angle and the threshold for water was set using bimodal histogram analysis by expert evaluation for each tile. Accuracy assessment of flood maps derived from Sentinel-1 compared to Sentinel-2 was reliable with the overall kappa coefficient being 0.78 .

Our study reviled that different sources of data can give controversial information about the possible flooded area extent along the rivers. However, the performed study confirmed that the maps of recurrently flooded areas retrieved from statistical analysis of Sentinel-1 and Sentinel-2 data along Estonian riverbanks can be effectively used as complementary information for defining the recurrent flooding zone in addition to national Topography maps. Therefore, the flood extent maps retrieved from Sentinel-1 and -2 were provided to decisionmakers in the public sector responsible for general spatial planning of municipalities in Estonia. In addition to spatial planning applications and statistical analysis, the remotely sensed Sentinel-1 SAR and Sentinel-2 multispectral data can be used for local-scale operational flood monitoring services. The remotely sensed flood extent and spatio-temporal variability data enables to understanding the flood dynamics that is the basis for developing climate change mitigation measures.

\section{ACKNOWLEDGEMENTS}

The authors are grateful to Estonian Ministry of the Environment and Estonian Environment Agency for supporting the study and defining the user requirements. This study was financially supported by the European Regional Development Fund within National Programme for Addressing SocioEconomic Challenges through R\&D (RITA). Authors are also grateful to Sander Rikka for performing UAV flights at Soomaa floodplain.

\section{REFERENCES}

Brisco, B., R., Touzi, J. J., van der Sanden, F. Charbonneau, T. J., Pultz, D'Iorio. M., 2008: Water Resource Applications with RADARSAT-2 - a Preview. International Journal of Digital Earth 1 (1), 130-147.

Chini, M., Hostache, R., Giustarini, L., Matgen, P., 2017: A hierarchical split-based approach for parametric thresholding of SAR images: flood inundation as a test case. IEEE Trans Geosci Remote Sens, 55(12), 6975-6988 DOI:10.1109/TGRS.2017.2737664

Clement, M. A., Kilsby, C. G., Moore, P., 2017: Multi-temporal synthetic aperture radar flood mapping using change detection, Journal of Flood Risk Management, 1-17.

Du, Y., Zhang, Y., Ling, F., Wang, Q. Li, W., Li, X., 2016: Water Bodies Mapping from Sentinel-2 Imagery with Modified Normalized Difference Water Index at 10-m Spatial Resolution Produced by Sharpening the SWIR Band. Remote Sensing, 8(4) 354, 1-19.

Feyisa, G.L., Meilby, H., Fensholt, R., Proud S.R. 2014: Automated water extraction index: a new technique for surface water mapping using Landsat imagery. Remote Sensing of Environment 140, 23-35.

Henry, J., Chastanet, P., Fellah, K., Desnos, Y.-L., 2006: Envisat Multi-Polarized ASAR Data for Flood Mapping. International Journal of Remote Sensing, 27 (10), 1921-1929.

Lode, E., 2012. Estimation of Estonian wetlands status and determination of their management options. Project report, Tallinn University, Institute of Ecology. https://www.etis.ee/Portal/Projects/Display/41a45722-6bd84d95-abe8-d1ed8d34f5a5?lang=ENG

Manjusree, R., Kumar L.P., Bhatt, C.M., Rao G.S., Bhanumurthy V., 2012: Optimization of threshold ranges for rapid flood inundation mapping by evaluating backscatter profiles of high incidence angle SAR images. International Journal of Disaster Risk Science, 3, (2), 113-122.

Martinis, S., Kersten, J., Twele, A., 2015: A fully automated TerraSAR-X based flood service. ISPRS Journal of Photogrammetry and Remote Sensing, 104, 203-212.

Martinis, S., Twele, A., Voigt, S, 2009: Towards Operational near Real-Time Flood Detection Using a Split-Based Automatic Thresholding Procedure on High Resolution TerraSAR-X data. Natural Hazards and Earth System Sciences 9: 303-314. 
Pham-Duc, B., Prigent, C., Aires, F., 2017: Surface water monitoring within Cambodia and the Vietnamese Mekong delta over a year, with Sentinel-1 SAR observations. Water, 9, 366.

Pulvirenti, L., Pierdicca, N. Chini, M., Guerriero. L., 2011: An Algorithm for Operational Flood Mapping from Synthetic Aperture Radar (SAR) Data Using Fuzzy Logic. Natural Hazards and Earth System Sciences 11: 529-540. doi:10.5194/nhess-11-529-2011.

Sanyal J., Lu X.X., 2004: Application of remote sensing in flood management with special reference to monsoon Asia: a review. Natural Hazards, 33, (2), 283-301.

Thenkabail, P. S., 2016: Remote sensing of water resources, disasters, and urban studies. Boca Raton: CRC Press.

Twele, A., Cao, W., Plank, S. \& Martinis, S., 2016: Sentinel-1 based flood mapping: a fully automated processing chain. International Journal of Remote Sensing, 27 (13): 2990-3004.

Voormansik, K., X-band synthetic aperture radar applications for environmental monitoring, $\mathrm{PhD}$ dissertation, University of Tartu, 2014

Zalite, K., Radar Remote Sensing for Monitoring Forest Floods and Agricultural Grasslands, $\mathrm{PhD}$ dissertation, University of Tartu, 2016.

Geudtner, D., Torres, R., Snoeij, P., Davidson, M. and Rommen, B., 2014. Sentinel-1 system capabilities and applications. In 2014 IEEE Geoscience and Remote Sensing Symposium, 1457-1460.

Zoka, M., Psomiadis, E. and Dercas, N., 2018: The complementary use of optical and sar data in monitoring flood events and their effects. In Multidisciplinary Digital Publishing Institute Proceedings 2(11), 644.

Xu H.Q., 2006: Modification of normalised difference water index (NDWI) to enhance open water features in remotely sensed imagery. International Journal of Remote Sensing, 27, (14), 3025-3033. 